\title{
Modelagem da informação para a regulação urbanística dos assentamentos precários em Fortaleza
}

\author{
City information modeling for urban regulation of squatter settlements in Fortaleza-Brazil
}

Mariana Quezado Costa Lima[a] [D, Clarissa Figueiredo Sampaio Freitas[b] [D,

Daniel Ribeiro Cardoso $[\mathrm{b}]$ id

[a] Universidade Federal do Ceará (UFC), Departamento de Arquitetura, Urbanismo e Design, Fortaleza, CE, Brasil [b] Universidade Federal do Ceará (UFC), Departamento de Arquitetura, Urbanismo e Design, Fortaleza, CE, Brasil

Como citar: Costa Lima, M. Q., Freitas, C. F. S., \& Cardoso, D. R. (2019). Modelagem da informação para a regulação urbanística dos assentamentos precários em Fortaleza. urbe. Revista Brasileira de Gestão Urbana, v. 11, e20180199. https://doi.org/10.1590/2175-3369.011.e20180199

\section{Resumo}

Estudos recentes estabeleceram o papel das políticas de planejamento urbano em alimentar o crescimento dos assentamentos precários nas cidades brasileiras, através da exclusão socioespacial dos moradores de baixa renda. As dificuldades de reverter a lógica excludente se devem a vários e complexos fatores políticoeconômicos e culturais. Discutimos aqui um fator pouco presente na literatura nacional: o modo de representação da cidade que tende a iluminar seletivamente as questões urbanas. Problematizando a questão da informalidade urbana em Fortaleza, aplicamos uma metodologia que combina geoprocessamento e modelagem da informação, para subsidiar a redefinição das regras urbanísticas para assentamentos precários de origem informal. Esse procedimento revelará não apenas a extensão das inadequações dos atuais códigos de uso e ocupação do solo, como também apresentará algumas potencialidades do uso de técnicas de modelagem da informação da cidade para informar sua redefinição.

Palavras-chave: Assentamentos precários. Informalidade urbana. Regulação urbana. Modelagem da informação. Forma urbana.

\begin{abstract}
Recent studies have established the role of urban planning policies in feeding the growth of informal settlements in Brazilian cities, through socio-spatial exclusion of low-income residents. The difficulties of reversing the exclusionary logic are due to several complex political, economic and cultural factors. We discuss here a factor very little discussed in the national literature: the mode of representation of the city, and in particular the invisibility of the informal city. We develop this argument from the case of Fortaleza, using documental analysis of urban plans and spatial analysis on the scale of the city and a neighbourhood. We apply a methodology that combines geoprocessing and information modeling to produce data. These data highlight the enormous distance between urban regulations and the actual urban form, and serve as a subsidy for the redefinition of urban rules for informal settlements through the Special Zones of Social Interest (ZEIS).This
\end{abstract}

MQCL é arquiteta e urbanista, mestra em Arquitetura e Urbanismo, e-mail: marianaqcl@gmail.com

CFSF é arquiteta e urbanista, doutora em Arquitetura e Urbanismo, e-mail: clarissa@arquitetura.ufc.br

DRC é arquiteto e urbanista, doutor em Comunicação e Semiótica, e-mail: danielcardoso@ufc.br 
methodology revealed both, the inadequacy of current zoning codes but also discuss some potentialities of geographic information modeling to subsidize their re-definition.

Keywords: Informal settlements. Urban regulation. Information modeling. Urban form.

\section{Introdução}

A narrativa dominante sobre a questão urbana brasileira muitas vezes sintetiza a precariedade habitacional associada à informalidade como resultado da ausência do estado, "como produto da omissão do poder público, sob a alegação de incapacidade administrativa" (Smolka, 2003, p. 2). Esse discurso exime o estado de suas responsabilidades perante os habitantes mais vulneráveis e ignora os conflitos envolvendo os vários agentes da produção do espaço urbano (Maricato, 2013; Villaça, 1995). Ignora que a atuação do estado não é neutra, mas tende a refletir os interesses dos agentes dominantes. A literatura recente sobre o assunto tem desafiado essa narrativa. Diversos autores têm sugerido que a informalidade não é uma consequência da ausência do estado, mas é frequentemente promovida por agentes estatais ou tacitamente permitida (Roy, 2005; Roy \& Alsayyad, 2004; Rolnik, 2015; Martins, 2006; Fernandes, 2012). Como contribuição a esse debate, problematizamos aqui um aspecto muito pouco reconhecido nessa discussão: o modo de representação oficial da cidade, que tende a iluminar seletivamente as diversas questões urbanas. No que se refere ao conceito de informalidade, em particular, há uma clara seletividade na definição de onde essa seria uma questão problemática.

As novas tecnologias da informação têm se mostrado importantes para expor questões relacionadas à justiça espacial. É importante considerar, entretanto, que cidades com origem largamente informal, como Fortaleza, apresentam um grave quadro de desinformação urbanística. Em um contexto de sobrecarga de dados (Castells, 1999), falar em desinformação pode parecer contraditório, embora bastante recorrente em diversas metrópoles globais. Para discutir e superar tal obstáculo, desenvolvemos aqui alguns procedimentos metodológicos que investigam os processos de produção dos assentamentos precários e que visam, em última instância, produzir subsídio para políticas de regulação urbanísticas mais condizentes com a realidade urbanística existente.

0 trabalho apresenta um método de visualização e representação da forma urbana, aplicado tanto na escala da cidade quanto na escala do bairro. Na escala da cidade são analisados (1) os documentos legais oficiais, de modo a identificar a abordagem do fenômeno da informalidade, e (2) os dados oficiais georreferenciados, de modo a confrontá-los com os documentos legais vigentes. Essas análises preliminares evidenciaram a necessidade de um método para mensurar a forma urbana de assentamentos precários, o qual foi aplicado a um conjunto de assentamentos periféricos designados como ZEIS pelo atual Plano Diretor Participativo de Fortaleza (CMFor, 2009), a ZEIS Bom Jardim. A escolha desta área, especificamente, deve-se à cooperação que vem se desenvolvendo desde 2013 com a Rede de Desenvolvimento Local Integrado e Sustentável do Grande Bom Jardim (Rede DLIS). Essa cooperação, favorecida pela forte organização comunitária presente no território, possibilitou o acesso às lideranças locais e, consequentemente, aos moradores. Para aproximar-se da área de estudo, em uma espécie de controle do método proposto, realizamos oficinas, questionários e visitas técnicas, entre março e junho de 2017, relativas à elaboração de um plano popular de urbanização para a área (Freitas et al., 2019), as quais não serão detalhadas neste artigo.

Assim, partindo da premissa de que a falta de informações urbanísticas contribui e alimenta o processo de urbanização desigual (Freitas et al., 2013), e reconhecendo que a tecnologia avança mais rápido que a sua aplicação em problemas reais da cidade (Pereira \& Silva, 2001), apresentamos uma metodologia de modelagem da informação capaz de superar esse obstáculo. Na primeira sessão, discutimos - na dimensão teórica - as implicações sociais de um contexto de relativa opacidade da cidade informal. Na segunda sessão, exploramos as implicações sociais do cenário de desinformação urbanística a respeito da informalidade urbana em Fortaleza, utilizando análise documental e análise quantitativa/espacial de dados oficiais sobre a cidade. Na seção final, apresentamos o método de modelagem da informação e a sua aplicação no território da ZEIS Bom Jardim. Esse procedimento revelará não apenas a extensão das inadequações dos atuais códigos de uso e ocupação do solo, como também apresentará algumas potencialidades do uso de técnicas de modelagem da informação da cidade para informar sua redefinição. 


\section{A cidade informal é opaca}

Para entender o fenômeno da informalidade urbana faz-se necessário refletir sobre o conceito de informalidade. Adotaremos aqui a definição de Castells \& Portes (1989, p. 12) que apresenta a informalidade como uma atividade que "não é regulada pelas instituições da sociedade, em um ambiente legal e social em que atividades similares são reguladas". Por essa definição a informalidade está, assim, intrinsecamente ligada à regulação. Essa interpretação, ao mesmo tempo em que oferece um risco de naturalizar a dicotomia entre formalidade e informalidade, tem a vantagem de requerer que se especifique o aparato regulatório em questão (Kanbur, 2009). 0 que é formal e o que é informal é uma construção social e parte do um contexto histórico, político e social específico.

Entendemos regulação urbanística como o conjunto de normas de parcelamento, uso e ocupação do solo, as quais são frequentemente aplicadas sob a forma de zoneamentos em planos diretores. Esses códigos afetam a distribuição social do território urbanizado ao definir as condições e parâmetros que estabelecem o limiar para o que é considerado um assentamento formal (Martins, 2006; Magalhães, 2013). Martins (2006) defende que o grande número de assentamentos informais precários em cidades dos países em desenvolvimento é causado não apenas pelas condições de pobreza dos habitantes, mas também, e principalmente, por um processo excludente de produção do espaço urbano.

Embora o status de informalidade não seja restrito à população pobre, não raro a existência da informalidade dos pobres é utilizada para justificar benefícios e anistias a setores sociais hegemônicos. Um processo de aplicação seletiva da lei urbanística não se restringe à realidade brasileira (Maricato, 2013; Freitas, 2014) e tem sido identificado em diversos contextos geográficos, como nos Estados Unidos (Mukhija \& Loukaitou-Sideris, 2015), no Sul da Ásia e no Oriente Médio (Roy \& Alsayyad, 2004). Nesse contexto, conhecer e sistematizar as características das atividades informais possui uma grande relevância política, tendo em vista sua capacidade de revelar o tratamento diferenciado do estado para com os diversos setores sociais.

Encontramo-nos em um momento histórico em que somos sobrecarregados de informações digitais e espacializadas, mas paradoxalmente constata-se um contexto de significativa desinformação urbanística. Uma desinformação seletiva e simbólica da cidade informal, a qual Roy (2009) chama de "un-mapping", ou seja, uma estratégia calculada por parte do estado para perpetuar um contínuo estado de exceção em políticas de uso e ocupação do solo em diversas cidades dos países em desenvolvimento ${ }^{1}$.

Na escala global o geógrafo Santos (2008) afirma que a informatização ou a "informacionalização" do espaço - dentro do contexto de globalização - não é uniforme e traz consigo um novo tipo de exclusão, a desigualdade da ciência, da tecnologia e da informação, a qual é reflexo e condicionante da exclusão socioespacial. Tendo em vista essa desigualdade, o autor diferencia "espaços luminosos" - áreas com grande densidade de informação - de "espaços opacos" - áreas praticamente vazias (Santos, 2008, p. 48).

Levando essa análise para a escala da cidade, a cidade informal pode ser considerada opaca (Costa Lima, 2017), em oposição ao conceito de transparência como acesso à informação, já que praticamente não há transmissão de informações sobre ela. Apesar de ocuparem grande parte das cidades brasileiras, os assentamentos precários estão ausentes dos mapas, registros e estatísticas oficiais, enquanto a estruturação de áreas de alta renda é extremamente detalhada em dados oficiais e códigos legais (Rolnik, 2015).

Para Roy (2005) e Maricato (2013) a falta de visibilidade dos assentamentos precários nas políticas urbanas é funcional e constitui um importante instrumento para o exercício arbitrário do poder, o qual permite ao estado "[...] determinar o que é informal e o que não é, e determinar que formas de informalidade irão prosperar e quais desaparecerão. 0 poder estatal é reproduzido através da capacidade de construir e reconstruir categorias de legitimidade e ilegitimidade" (Roy, 2005, p. 149).

Uma dimensão importante nesse processo de definição das categorias de legitimidade urbanística é o monopólio estatal na representação da realidade urbana. Com o aprimoramento das técnicas de modelagem da informação esse cenário se altera drasticamente. Em particular, no caso da informalidade urbana, as novas tecnologias constituem uma grande oportunidade de não focar apenas na cidade formal que foi previamente desenhada. Os avanços tecnológicos na representação do espaço urbano permitem medir a distância entre a cidade ideal/planejada e a cidade real, e assim evidenciar desigualdades e privilégios. Nesse sentido, Freitas

${ }^{1}$ No Brasil, Rolnik (2015) e Vainer (2011) desenvolvem esse argumento do estado de exceção das políticas públicas urbanas. 
et al. (2013) argumentam que, embora longe de ser suficiente para resolver o problema da exclusão socioespacial, o acesso à informação consiste em um poderoso instrumento de controle social na luta contra as políticas urbanas excludentes.

Nos últimos anos, no Brasil, temos assistido a um crescente interesse na questão do acesso à informação e da transparência em relação à administração pública. Além disso, com a institucionalização da agenda de reforma urbana no Brasil, foram feitos esforços para mitigar a opacidade relativa aos assentamentos precários por meio da produção de dados sobre eles (Ancona, 2010). 0 Brasil está vários passos à frente de outros países em desenvolvimento, à medida que avança na definição de assentamentos precários, a fim de operacionalizar uma política para eles. Essa política exigiu que cada município desenvolvesse um Plano de Habitação de Interesse Social (PLHIS) como condição para acessar o Fundo Nacional de Habitação de Interesse Social (FNHIS) criado em 2005. Embora tenha havido um esvaziamento do FNHIS com o lançamento do Programa Minha Casa Minha Vida em 2009, uma parcela significativa dos municípios elaborou seus respectivos planos (Moreira \& Ribeiro, 2016). Nos municípios que realizaram esses planos avançou-se na identificação dos tipos de precariedade dos assentamentos informais de baixa renda, tornando esses documentos importantes fontes de informação sobre a questão habitacional local. Entretanto pesquisas realizadas sobre os processos de elaboração desses planos revelam dificuldades operacionais relacionadas à ausência de informações. Após pesquisar realidade institucional dos municípios de São Paulo, Denaldi \& Fonseca (2012, p. 31) apontaram para a persistência do problema do limitado conhecimento da precariedade habitacional no território municipal:

A maioria dos Planos não apresenta o mapeamento do conjunto dos assentamentos. São raros os municípios que possuem algum tipo de informação georreferenciada. As metodologias para caracterização da precariedade habitacional, sobretudo o material produzido pelo MCidades, poderiam ser melhor apropriadas pelos municípios.

Portanto, ainda que se verifiquem movimentos de "iluminação" dos espaços informais opacos, os assentamentos precários continuam a aparecer nos mapas da cidade na forma de grandes "manchas" no mapa, o que contraria sua diversidade e complexidade. Falta sistematizar dados sobre a forma urbana e o ambiente construído dos assentamentos precários e transformar esses dados em informação.

\section{Assentamentos informais (precários?) em Fortaleza}

Fortaleza, capital do estado do Ceará, em menos de seis décadas quintuplicou sua população de 514 mil habitantes em 1960 para cerca de 2,4 milhões em 2010 (IBGE, 2010). É considerada a quinta maior cidade do país e também a quinta cidade mais desigual do mundo (Un-Habitat, 2011). A violência e a precariedade estão concentradas nos assentamentos precários de baixa renda, que, segundo números oficiais, abrigam mais de $40 \%$ da população atual (Fortaleza, 2016).

Uma rápida análise dos documentos históricos de planejamento revela que a informalidade urbana enquanto fenômeno é raramente citada pelos planos que nortearam o desenvolvimento urbano de Fortaleza2: dos oito documentos analisados, apenas três mencionaram o processo. Durante a segunda metade do século XX, embora as contradições e desigualdades socioespaciais estivessem se espalhando na cidade, os planos continuaram a lidar com modelos ideais, assumindo um território livre de conflitos. Ou fingiam que a cidade informal não existia ou, ao reconhecer sua existência, reforçavam concepções estigmatizadas. O Plano Diretor de 1963, por exemplo, coloca a culpa do "problema das favelas" nos próprios moradores, referindose a eles como pessoas com poucas habilidades e que têm dificuldade em melhorar suas vidas e se adaptar à vida urbana, "daí criarem problemas sociais de mendicância, prostituição, infância abandonada, delinquência e 'favelização'" (CMFor, 1963, p. 34). Em outra passagem, o plano refere-se aos moradores informais como "párias", o que, por definição, significa aqueles que não cumprem seu papel social ou aqueles que não têm os mesmos direitos que os outros.

\footnotetext{
${ }^{2}$ Os documentos analisados foram em sua maioria de dois tipos: códigos de postura (Decreto n. 70, 1932; Lei n. 188, 1950; Lei n. 5530, 1981) e planos diretores (Lei n. 2128, 1963; Lei n. 5122, 1979; Lei n. 7061, 1992; Lei n. 062, 2009).
} 
Outros documentos oficiais de planejamento estabeleciam padrões higienistas que estavam muito acima da realidade dos migrantes recentes do campo empobrecido. Esses padrões, provavelmente importados dos regulamentos urbanos europeus, assim como em outras cidades brasileiras (Rolnik, 1997), exigiam moradias unifamiliares isoladas em grandes lotes, separadas da rua e dos vizinhos. De fato, esses códigos proibiam a coabitação e exigiam um tamanho de lote mínimo grande, o qual foi aumentado de 220 para 300 metros quadrados entre os códigos de 1932 (Prefeitura de Fortaleza, 1932) e 1950 (Prefeitura de Fortaleza, 1950), e mantido com o mesmo valor desde 1950 até o Plano Diretor de 1979 (CMFor, 1979), quando esse valor cai para $135 \mathrm{~m}^{2}$. Mesmo quando os planos estimularam a construção de casas a preços acessíveis, os códigos de postura limitaram essa construção a áreas fora do perímetro urbano e, portanto, fora do escopo da regulação.

Ao definir erroneamente o fenômeno da informalidade e desviar-se dos reais problemas estruturais que estavam por trás dele, os planos historicamente contribuíram para aumentar o problema da moradia precária. Quanto mais a realidade da informalidade era ignorada pelos planos, mais crescia e reiterava seu caráter explorador nos moradores de baixa renda.

As novas ferramentas tecnológicas associadas a informações de qualidade aparecem, todavia, como uma oportunidade de evidenciar desigualdades e privilégios, os quais eram oferecidos tanto sob a forma de produção de dados e construção de informações, quanto sob a forma de comunicação/difusão dessas informações. 0 presente trabalho foca nesse primeiro tempo de elaboração como condição primária para que o segundo momento aconteça, mas reconhece que apenas produção de informação, sem que ela seja devidamente repassada (e aqui importa também a forma como ela é repassada) à população, não é suficiente.

Em um contexto de avanço na disseminação de informações sobre a cidade de Fortaleza por parte de órgãos de planejamento do poder público municipal, ferramentas de geoprocessamento (como o software Qgis) nos permitiram demonstrar, por meio da manipulação de dados de terrenos e edifícios, que a não conformidade com as regulamentações não se restringe a assentamentos de baixa renda em Fortaleza.

Assim, verificamos que existem alguns edifícios de "alto padrão" que não cumprem com os parâmetros legais. Ao analisar a altura dos edifícios existentes na cidade, verificou-se que existem vários edifícios que excedem a altura máxima permitida pela regulamentação atual (ver Figura 1). Vale ressaltar que esses casos concentram-se principalmente nos bairros de alta renda da cidade, que já são as áreas mais permissivas em termos de altura máxima, que é de 72 metros nessas áreas. 


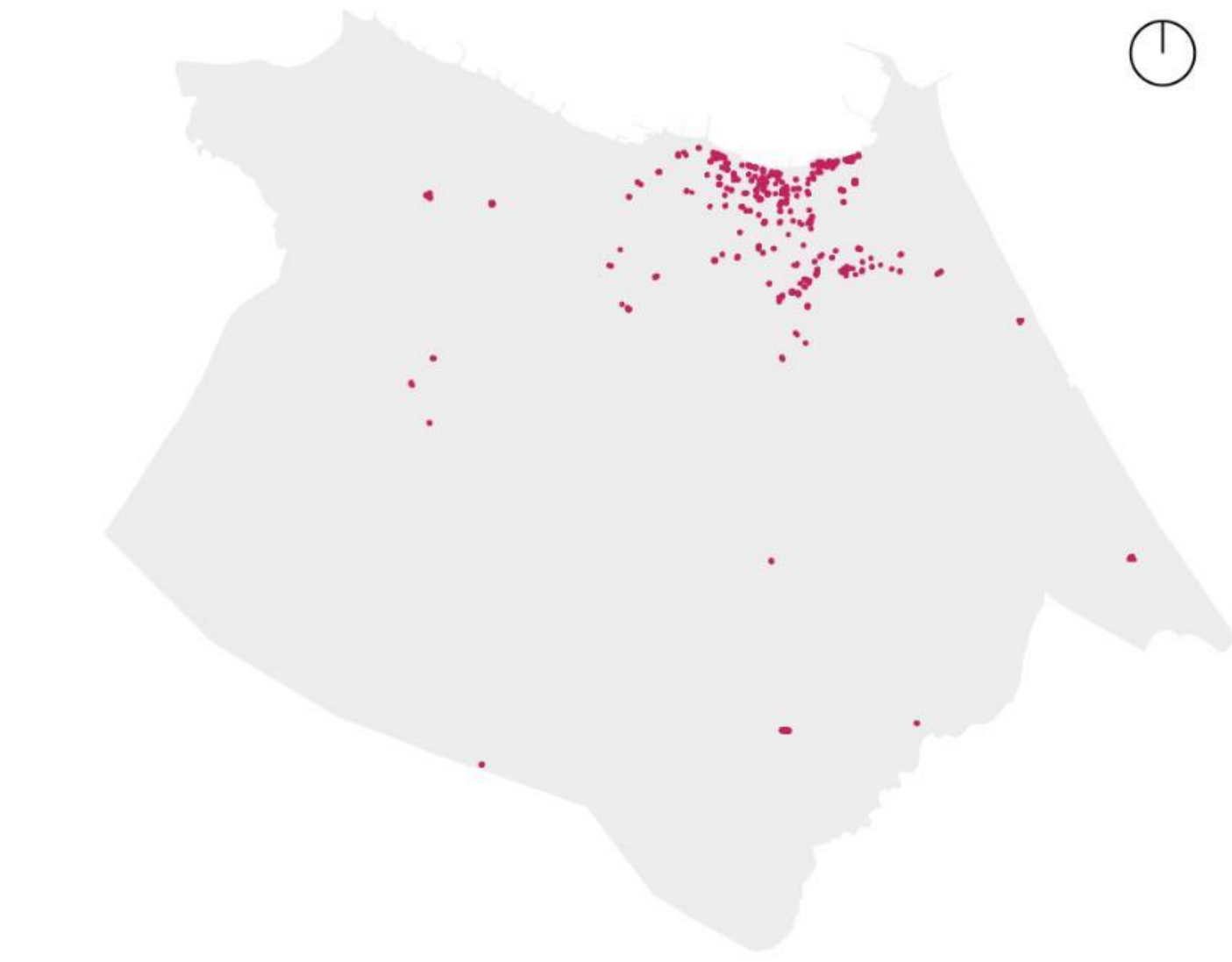

Figura 1 - Edifícios em Fortaleza cuja altura excede o máximo estipulado pela legislação vigente Fonte: elaborada pelos autores com base em dados da Prefeitura Municipal de Fortaleza (2010).

Embora o descumprimento da legislação urbana não se restrinja às famílias de baixa renda, são os assentamentos precários os espaços considerados ilegais pela sociedade e, como tais, permanecem invisíveis às políticas urbanas. As agências de planejamento urbano nem sequer produziram informações sobre seus atributos ou, se o faziam, as informações produzidas não são devidamente disponibilizadas à população. 0 banco de dados oficial da administração municipal de Fortaleza, utilizado para arrecadar impostos sobre a propriedade, é incompleto e tem vazios de tamanhos consideráveis que coincidem com espaços intensamente ocupados dos assentamentos precários. Como os dados em questão foram produzidos para fins fiscais, pode-se afirmar que os vazios ocorrem devido ao status de ilegalidade das áreas. No entanto, como esse banco de dados é a camada de base com a qual as agências de planejamento programam os investimentos urbanos no território, a falta de dados acaba nos informando qual parte da cidade é levada em conta.

Com o desenvolvimento do PLHIS de Fortaleza, tomamos conhecimento que 1.077.059 habitantes vivem em 856 assentamentos precários (Fortaleza, 2016), compreendendo 44\% da população total de Fortaleza (ver Figura 2). No entanto, enfrentar os desafios da ocupação informal da terra para a sobrevivência econômica exige mais e melhores dados do que a identificação de assentamentos precários. Mesmo que não atendam a padrões como tamanho de lote, recuos e/ou taxa de ocupação, seus ambientes construídos não são necessariamente "precários", alguns deles até têm posse legal da terra. Isolando apenas as parcelas fora de assentamentos precários (ver Figura 3), podemos perceber que grande parte da cidade não precária está fora do escopo da regulação urbana, ainda que consideremos apenas um parâmetro (área do lote). 


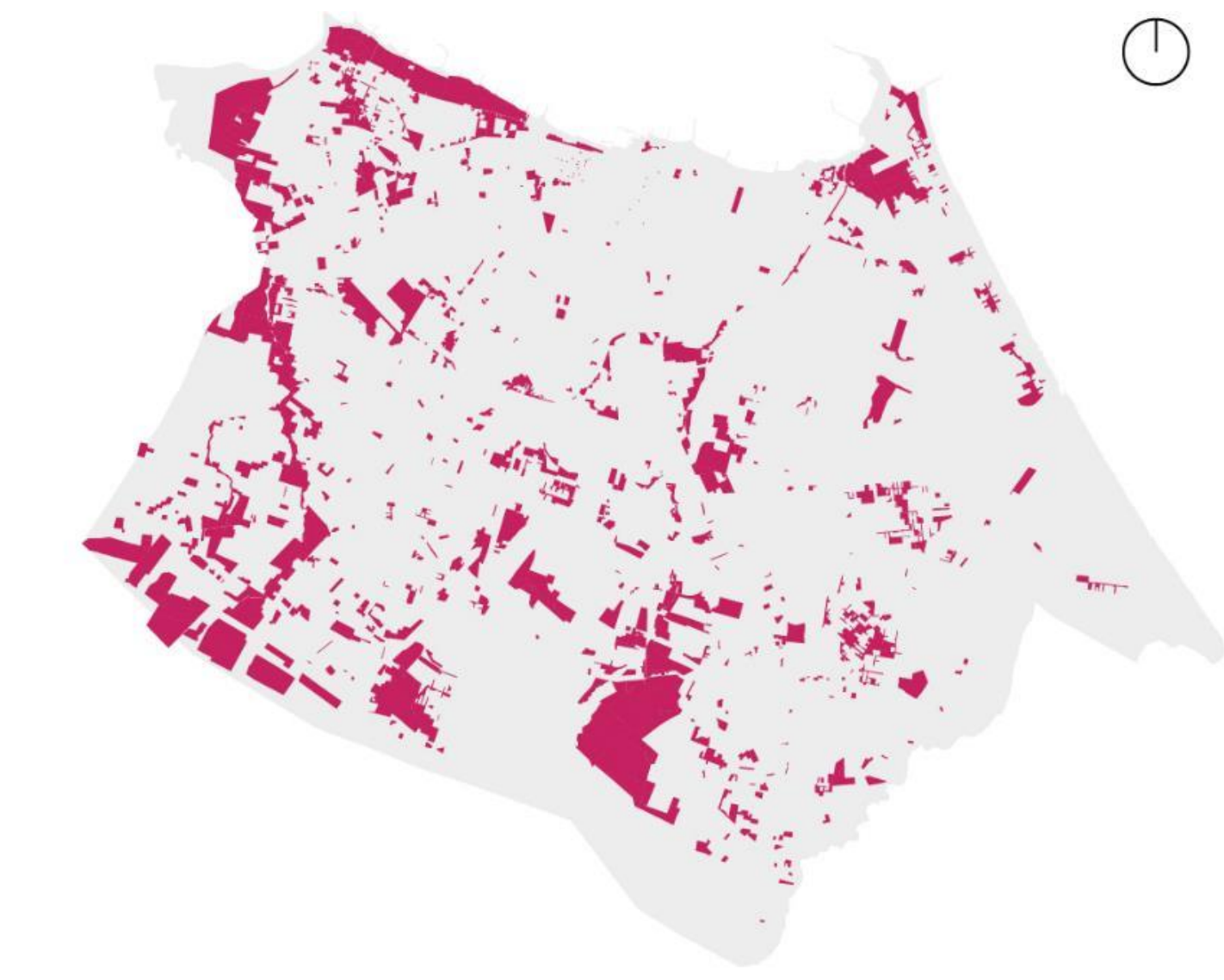

$\begin{array}{lllllll}0 & 1 & 2 & 3 & 4 & 5 \mathrm{Km}\end{array}$

LIMITES FORTALEZA

ASSENTAMENTOS PRECÁRIOS

Figura 2 - Assentamentos Precários em Fortaleza

Fonte: Elaborada pelos autores com base em dados de Fortaleza (2016). 


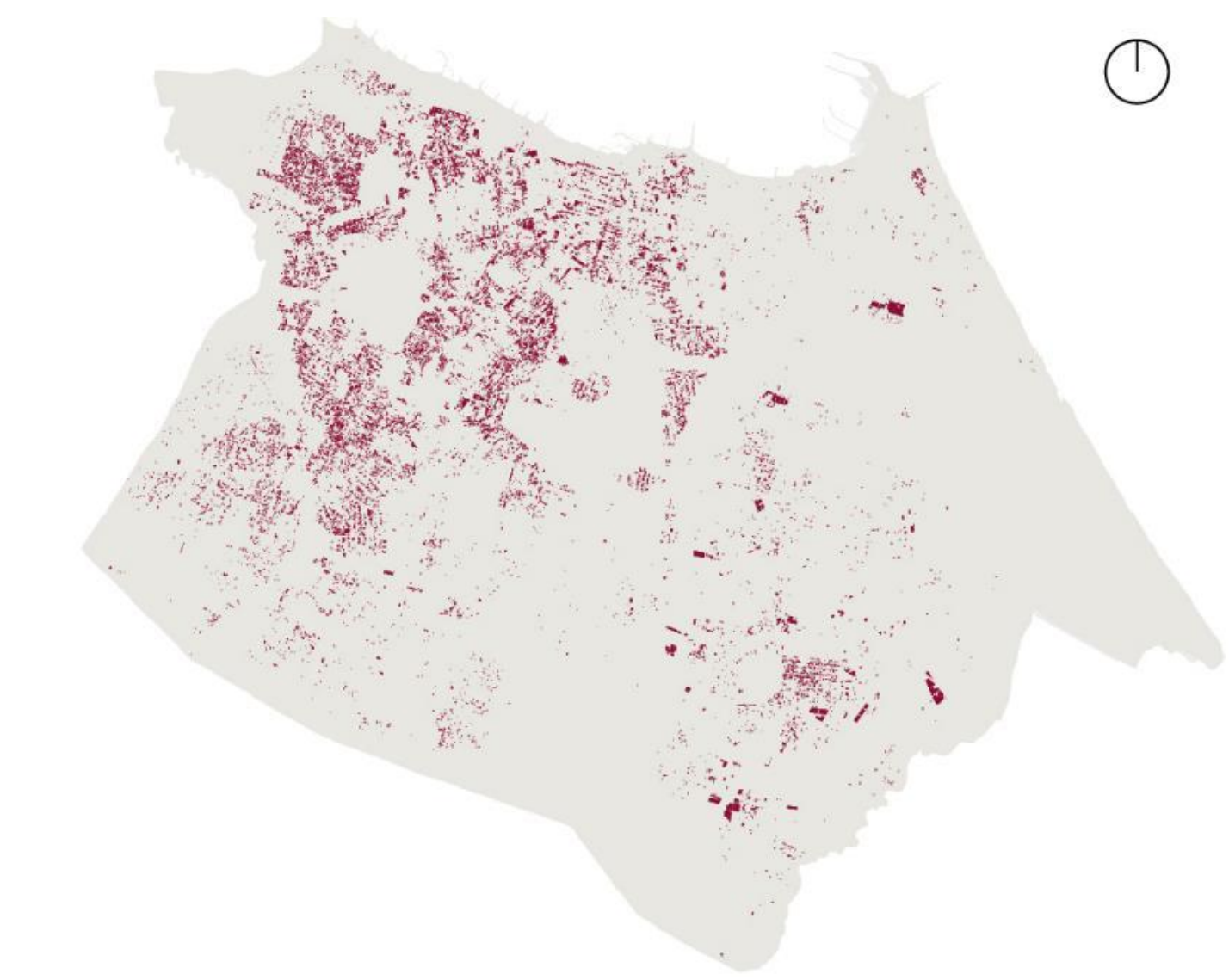

$\begin{array}{lllllll}0 & 1 & 2 & 3 & 4 & 5 \mathrm{Km}\end{array}$

LIMITES FORTALEZA

LOTES MENORES QUE O MÍNIMO PERMITIDO

Figura 3 - Lotes em Fortaleza cuja área está abaixo da mínima estipulada pela legislação vigente Fonte: elaborada pelos autores com base em dados da Prefeitura Municipal de Fortaleza (2010).

Mais de 50 mil lotes têm áreas abaixo do mínimo permitido pelo plano diretor vigente $\left(125 \mathrm{~m}^{2}\right)$. Esse número representa cerca de $20 \%$ do universo de lotes considerados. A área média do lote "não precário" é de $79 \mathrm{~m}^{2}$, portanto abaixo do mínimo de 125. Diversos estudos de pesquisadores locais têm apontado que uma das principais causas dessa divergência é possivelmente a incapacidade do mercado formal de responder adequadamente à necessidade de terras a preços acessíveis, visto que, entre outras coisas, a maior parte da população não pode pagar o preço do tamanho mínimo do lote (Pequeno \& Freitas, 2012). Vale ressaltar que, muitas vezes nas cidades latino-americanas, o metro quadrado de um lote informal é mais caro do que o metro quadrado de um formal, mas um lote com um tamanho menor (muitas vezes irregular) acaba tendo um preço total menor em comparação com o um formal (Smolka, 2003). Assim, lotes menores são uma das condições-chave para a viabilidade econômica de porções bem servidas da cidade para população de baixa renda.

Embora a informalidade urbana não seja restrita a assentamentos precários, é nesses assentamentos que a falta de conformidade com as normas urbanas assume sua forma mais perversa, visto que seus moradores são frequentemente privados de serviços em nome de seu status de ilegalidade. Na próxima seção examinaremos mais de perto a área designada como ZEIS, na periferia sudoeste de Fortaleza, a fim de aprofundar o significado político e as consequências materiais de se viver "fora do mapa". 


\section{ZEIS Bom Jardim: um território desconhecido}

A ZEIS Bom Jardim está localizada no sudoeste de Fortaleza e abrange partes dos bairros de Bom Jardim e Siqueira (ver Figura 4). Trata-se de uma região com um dos piores níveis de serviços de infraestrutura urbana, concentrando também importantes problemas sociais e ambientais. A falta de cumprimento das regulações urbanas e fundiárias na área é ainda mais acentuada do que na cidade como um todo. 0 processo de desenvolvimento urbano nessa região ocorreu por meio de loteamentos irregulares nos espaços mais adequados e ocupações clandestinas em áreas menos favoráveis à urbanização, como as margens do Rio Maranguapinho e seus afluentes (Freitas, 2019). Além disso, o território possui um dos piores índices de atendimento de redes de esgoto domiciliar e drenagem. Tudo isso em uma região cujos índices socioeconômicos, como renda e alfabetização, estão abaixo da média da cidade e com taxas de crescimento populacional superiores àquelas com melhor infraestrutura e serviços urbanos (IBGE, 2010).

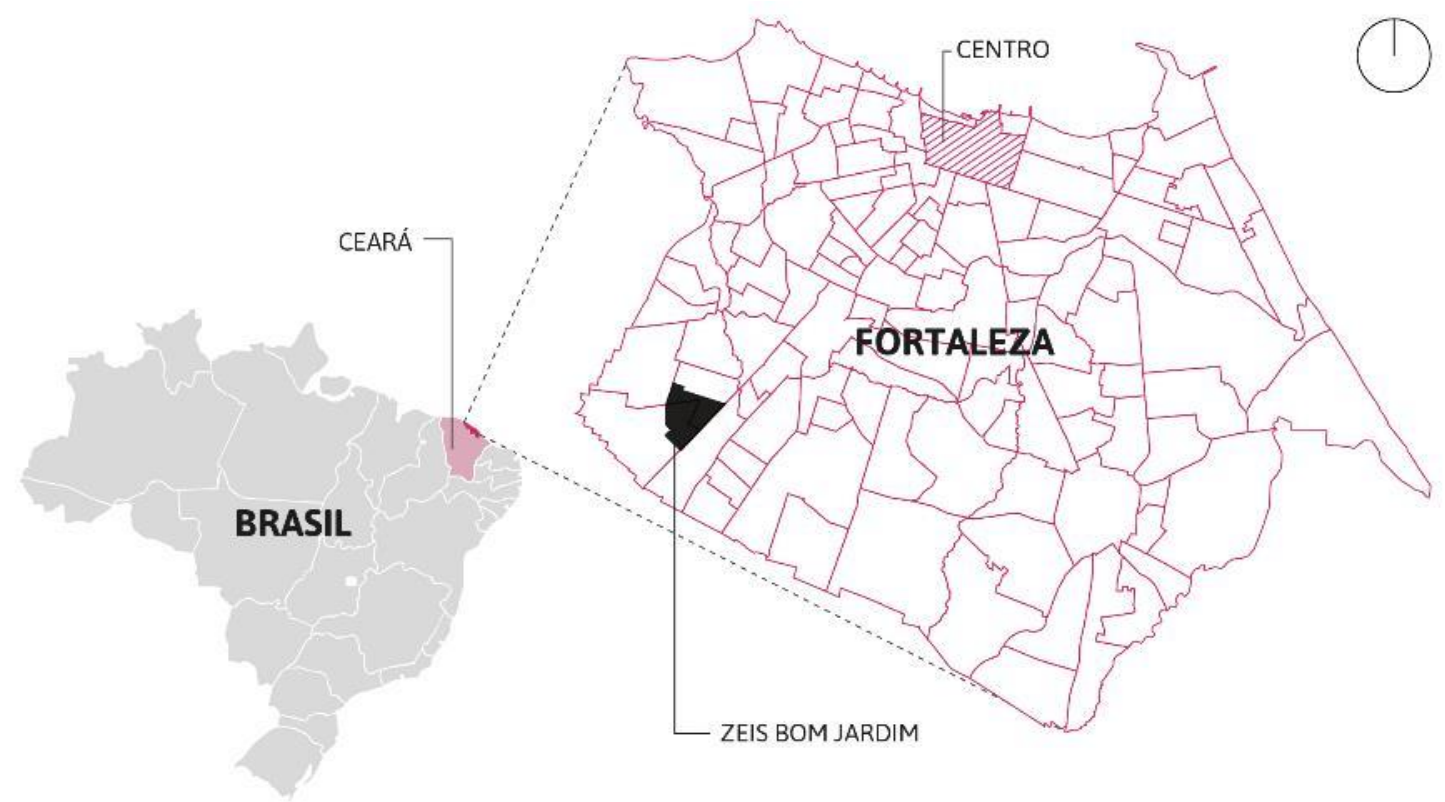

Figura 4 - Localização da ZEIS Bom Jardim em Fortaleza Fonte: Elaborada pelos autores com base em dados de Fortaleza (2009).

A despeito das altas taxas de crescimento populacional, sabe-se muito pouco sobre o processo de urbanização de território, suas tendências e seus desafios. Sem dúvida tal desconhecimento possui um papel em alimentar um intenso processo de estigmatização do território bastante presente na vida cotidiana dos moradores (Almeida, 2014; Bezerra, 2015). 0 fato de que constam apenas 2.107 lotes na base cadastral de lotes da Prefeitura Municipal de Fortaleza (2010) dentro do território da ZEIS, o que corresponde a 28\% do total de cerca de 7.500 lotes existentes no mesmo ano, revela como a área de estudo é desconhecida ao olhar do poder público responsável pela gestão urbana (ver Figura 5). É, portanto, um indicador da falta de vontade política do gestor público para direcionar o processo de urbanização na periferia urbana. 

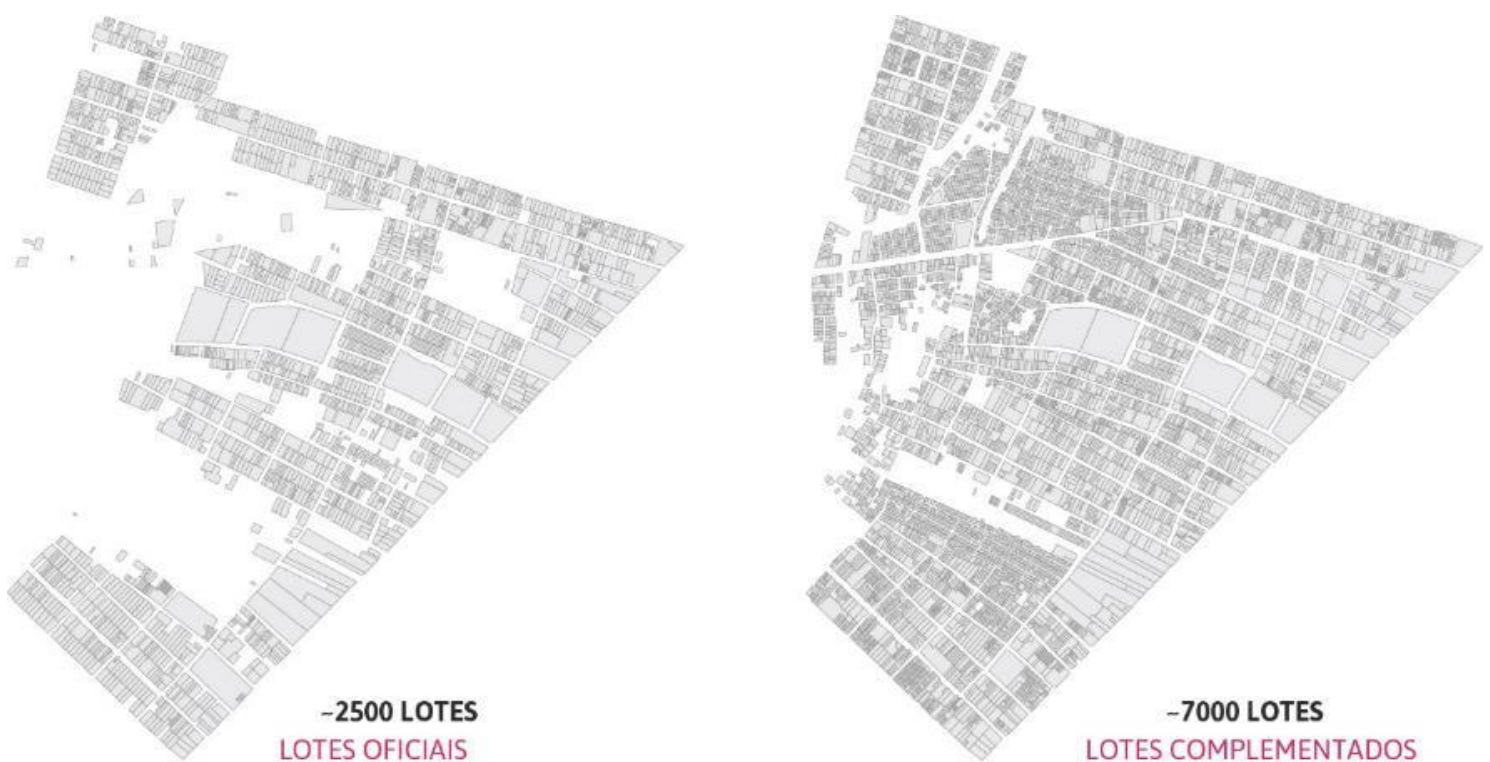

Figura 5 - Comparação entre o dado da geometria dos lotes de acordo com o cadastro oficial, e o mesmo dado depois do desenho dos lotes faltantes

Fonte: elaborada pelos autores com base em dados da Prefeitura Municipal de Fortaleza (2010).

No sentido de superar esse cenário de desinformação urbanística, apresentamos a seguir o método de modelagem da informação utilizado.

\section{O método: modelagem da informação da cidade}

O objetivo do método proposto é sistematizar as propriedades espaciais dos assentamentos precários para subsidiar sua regulação urbanística com foco na redução de alguns dos problemas enfrentados pelos moradores e levando em consideração as especificidades de cada situação. 0 método não exige um levantamento de cada habitação, permitindo desvendar a forma urbana dos assentamentos usando dados geométricos simples, extraídos de um levantamento fotogramétrico aéreo oficial.

Propõe-se sistematizar as características dos assentamentos tendo como ponto de partida os indicadores de densidade, como os propostos por Berghauser Pont \& Haupt (2010). Os pesquisadores holandeses argumentam que a densidade contém informações valiosas sobre propriedades espaciais, com potencial para ser um método capaz de articular aspectos quantitativos e qualitativos da forma urbana, desde que tenha indicadores bem definidos. Uma das razões para a utilização desse aparato teórico foi a correspondência de muitos dos indicadores por eles definidos com os parâmetros de planejamento urbano presentes na legislação brasileira, como Taxa de Ocupação, Índice de Aproveitamento e Altura da Edificação (Coverage, Building Intensity e Building Height, respectivamente). A abordagem desses autores foi estudada de modo a adaptá-la às particularidades da cidade informal de Fortaleza. A metodologia proposta será dividida em escalas, também adaptadas das aplicadas por Berghauser Pont \& Haupt (2010). A escala do lote é análoga à definida pelos autores holandeses ( $L o t$ ); a escala do tecido (Fabric) corresponderá a porções do território que apresentam algum grau de homogeneidade, que por vezes coincidirá com a delimitação de assentamentos precários; e a escala do distrito (District) corresponderá aos limites da ZEIS. Embora didaticamente classificadas, essas escalas estão intrinsecamente conectadas. Esse método foi concebido como parte de uma pesquisa mais ampla (Costa Lima, 2017), que, entre outras coisas, estabeleceu caminhos para medir diferentes aspectos da forma urbana, incluindo dimensões das vias e raios de abrangência de equipamentos urbanos. Este trabalho está concentrado nas medidas diretamente relacionadas às formas de ocupação das áreas privadas, como tamanho do lote, taxa de ocupação, o índice de aproveitamento e a altura do edifício, haja vista sua relação direta com a elaboração de normas urbanísticas.

0 método de modelagem da informação baseia-se empiricamente no Sistema Integrado de Modelagem da Informação da Cidade (Simic), desenvolvido por Sousa (2018). 0 sistema adotado tem como peça central um 
banco de dados (BD) remoto, alocado nos servidores da Universidade, que armazena tanto os dados secundários obtidos quanto os dados produzidos ao longo do processo. Como Sistema Gerenciador de Banco de Dados Relacional (SGBDR), o Simic utiliza o PostgreSQL, o qual tem uma grande capacidade de armazenamento e possibilidade de acessar porções do banco de dados e/ou modificá-lo por meio de consultas (queries) com uso da Linguagem de Consulta Estruturada (SQL). 0 sistema é capaz de armazenar e manipular dados espaciais georreferenciados graças à sua extensão PostGIS, que possibilita ainda uma conexão direta a um software SIG, como o Qgis.

A partir da base elaborada para o Simic desenvolvemos uma metodologia baseada em algoritmos. Algoritmo será entendido como o passo a passo para se resolver um problema em um número finito de etapas bem definidas, em que dados de entrada (inputs) passam por essas etapas e produzem dados de saída (outputs) e em que uma mudança nos dados de entrada - mudando a paisagem urbana analisada ou os valores dos parâmetros - gera automaticamente uma mudança nos resultados (Terzidis, 2004). Algumas mudanças no sistema também foram necessárias de acordo com as particularidades da metodologia deste trabalho (ver Figura 6), de modo que o software Qgis teve um papel de maior relevância que no Simic. 0 Qgis foi utilizado na importação dos dados secundários em formato shapefile para o BD bem como na sua edição e manipulação em tempo real por meio da extensão PostGIS. Foi igualmente utilizado para visualização bidimensional e análise de dados. Entretanto, nem todas as análises necessárias eram possíveis de se fazer no Qgis. Para tais análises utilizamos um modelador algorítmico (MA) Grasshopper 3D, que é um plug-in do Rhinoceros 3D, um software tipo CAD, ambos utilizados no Simic. Quanto ao software de análise estatística (SAE), apesar de algumas estatísticas simples poderem ser geradas com Qgis, para análises estatísticas mais complexas, foi utilizado o SPSS Statistics.

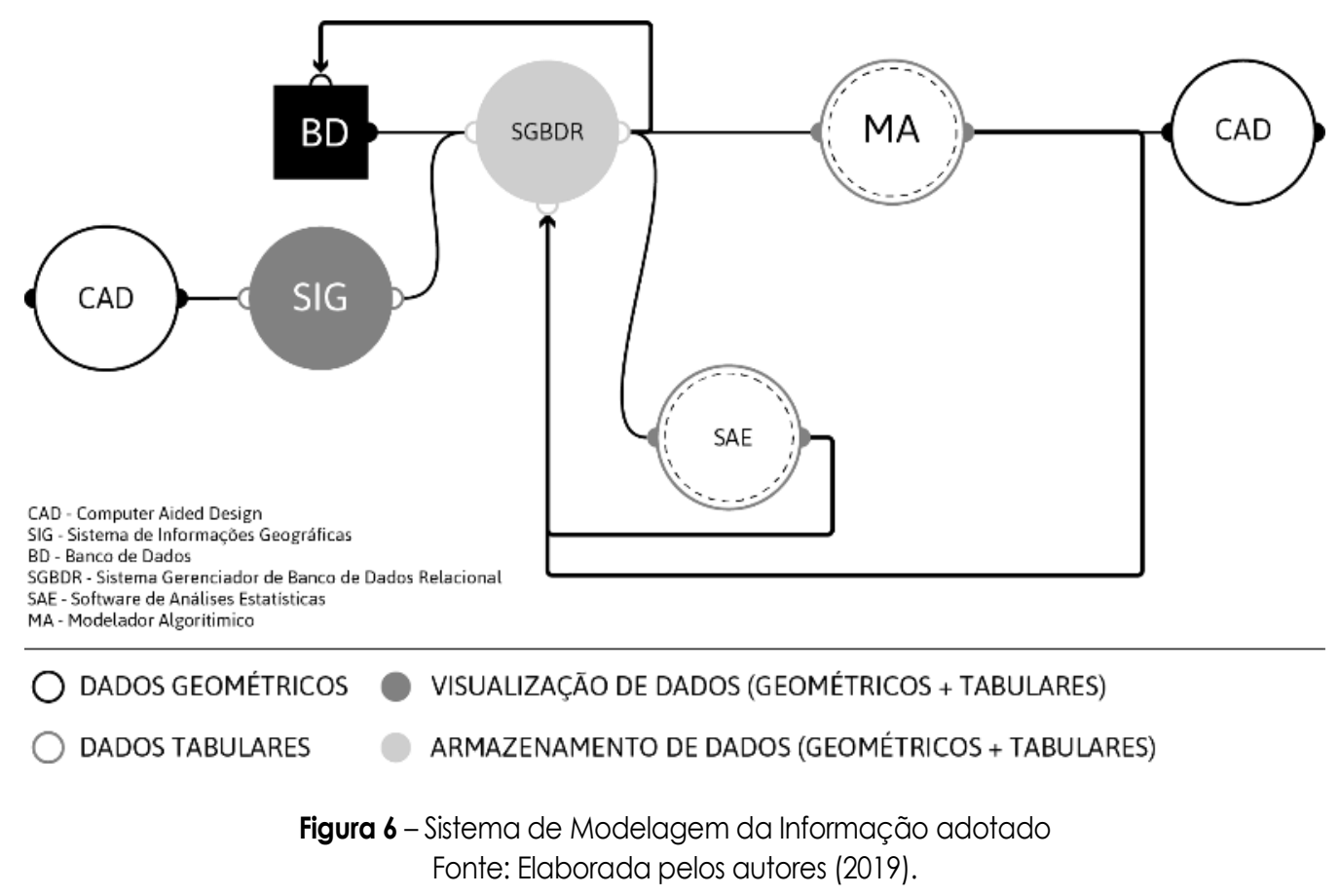

Para a análise da escala do lote (ver Figura 7) as geometrias de lotes e edifícios devem ser importadas para o Grasshopper. 0 algoritmo elaborado permite, em primeiro lugar, identificar os centroides, ou seja, os centros geométricos de cada edifício. Em seguida, o algoritmo analisa espacialmente em cada lote quais os centroides são internos à curva de delimitação do lote, o que gera um filtro de localização para os edifícios. É então possível calcular a área ocupada em cada lote. No entanto, para calcular a área construída, é necessário conhecer o número de andares, que é estimado dividindo-se a coluna de atributos com as alturas (em metros) por três metros - uma aproximação do pé-direito - e arredondando o resultado. A lista com o número de andares é submetida ao filtro de localização dos edifícios, permitindo o cálculo da área construída e a altura máxima em cada lote. Com os resultados da área ocupada e da área construída é possível calcular - dividindo 
os resultados pelas respectivas áreas dos lotes - a taxa de ocupação e o índice de aproveitamento, respectivamente. Embora os cálculos sejam feitos na escala do lote, não há necessidade ou viabilidade de realizar uma análise lote a lote. Os resultados obtidos devem ser usados para fornecer uma visão geral e comparativa das características de cada lote na escala da ZEIS e também para fundamentar a delimitação de tecidos.

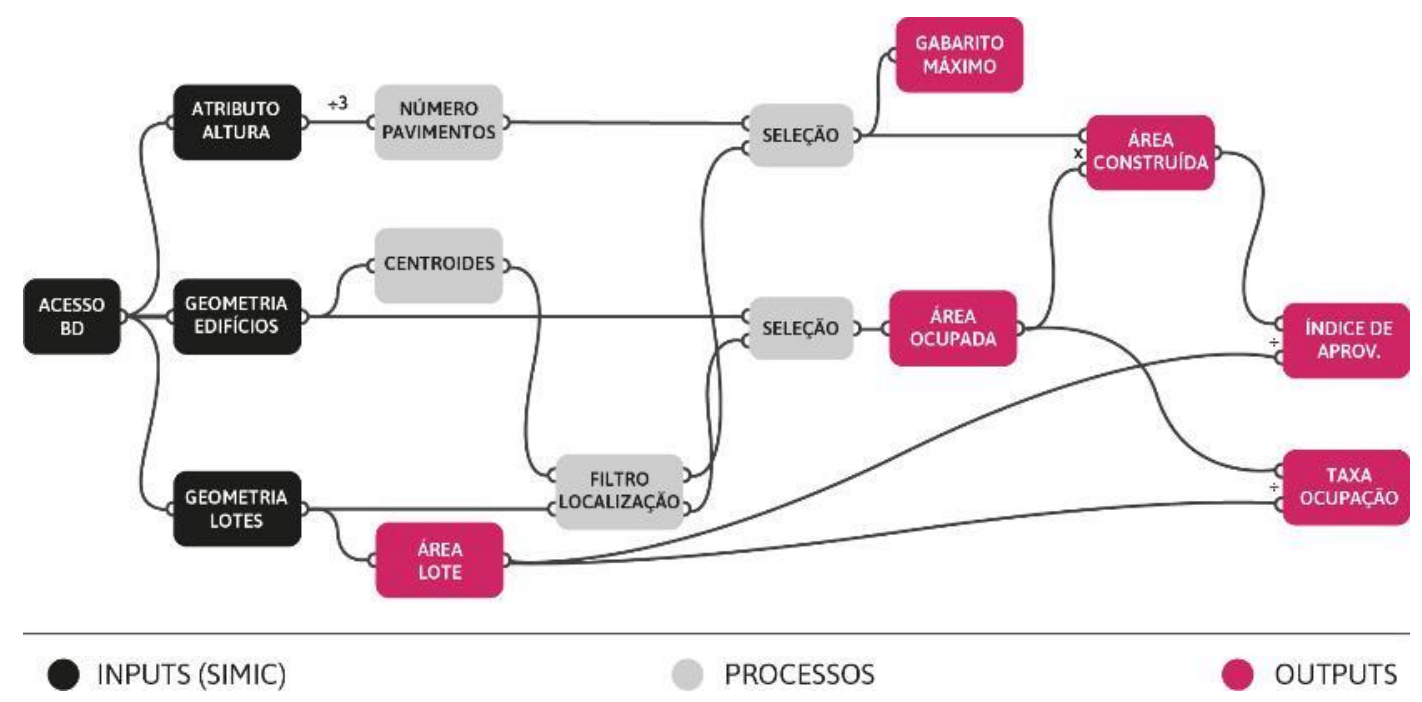

Figura 7 - Algoritmo para cálculo de indicadores por lote Fonte: Elaborada pelos autores (2019).

Para realizar a análise na escala do tecido, é necessário, antes de tudo, dividir o território a ser estudado em áreas com relativa homogeneidade internamente em termos de forma urbana. Uma vez que os tecidos foram delimitados, eles devem ser numerados, e esse número deve ser atribuído aos lotes de cada um dos tecidos. Em seguida, sugere-se utilizar um software de análises estatísticas, como o SPSS Statistics, para o qual importamos a tabela de atributos do lote, que já deve ser preenchida com os valores obtidos nos algoritmos Grasshopper para a escala de lote e a classificação em tecidos. Com o SPSS Statistics é possível gerar tabelas e gráficos com as frequências e porcentagens de cada indicador de acordo com categorias préestabelecidas. Com o mesmo software é possível analisar os dados para a escala da ZEIS.

\section{Resultados: a aplicação do método na Zeis Bom Jardim}

As principais fontes dos dados geométricos utilizados no estudo de caso foram um levantamento aerofotogramétrico feito pelo município em 2010 e shapefiles produzidos pelas autoridades municipais.

Verificou-se que parte dos assentamentos nunca foi oficialmente loteada. Portanto, essa parte não recebeu esforços do estado para reservar espaço para o sistema viário e outros espaços públicos. A falta de informação sobre os limites dos lotes existentes, previamente mencionada, demandou um processo extenso de manipulação de geometrias, uma vez que se verificou que a análise dos indicadores por meio do método supracitado necessitava, em primeiro lugar, da delimitação dos lotes (ver Figura 8). 0 processo de construção de dados, que deveria ter sido produzido e divulgado pelas instâncias públicas, foi um dos grandes desafios deste trabalho. 


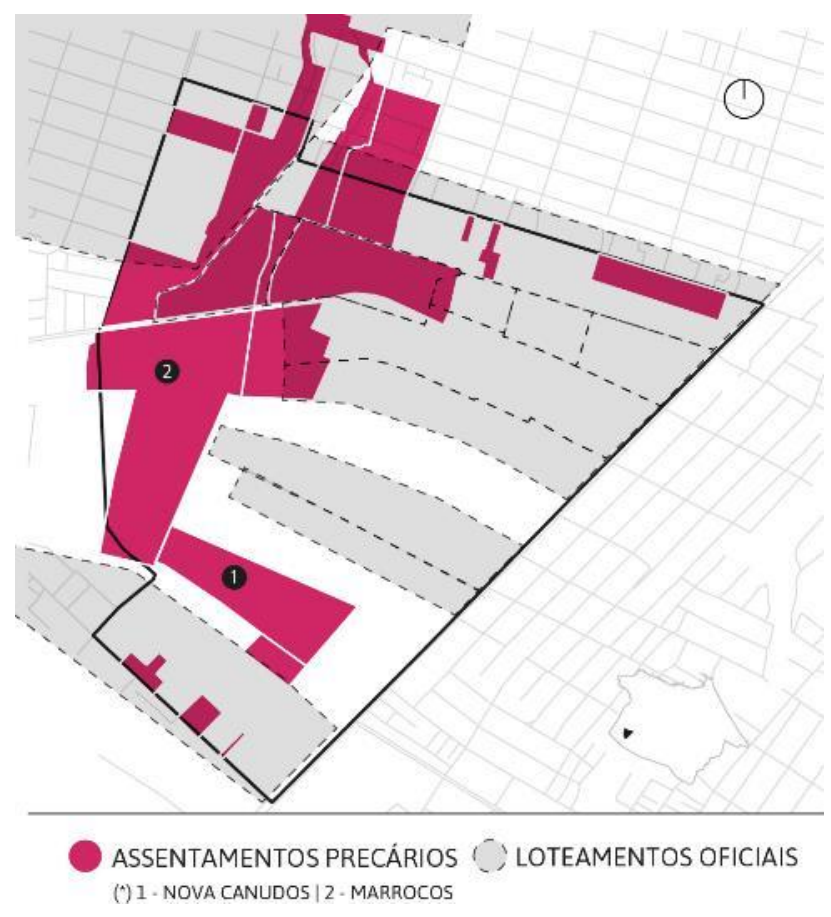

Figura 8 - Assentamentos precários e loteamentos oficialmente reconhecidos na ZEIS Bom Jardim Fonte: Elaborada pelos autores com base em dados da Prefeitura Municipal de Fortaleza (2016).

A partir dos dados de lotes e edifícios da ZEIS Bom Jardim os algoritmos foram aplicados gerando mapas dos indicadores de densidade. Aqui destacaremos os mapas com as medições das áreas dos lotes e das taxas de ocupação (ver Figura 9). Ao analisar esses mapas, 14 tecidos foram identificados. Ao contrário dos exemplos apresentados por Berghauser Pont \& Haupt (2010), praticamente nenhum dos tecidos da ZEIS Bom Jardim pode ser considerado totalmente homogêneo. 

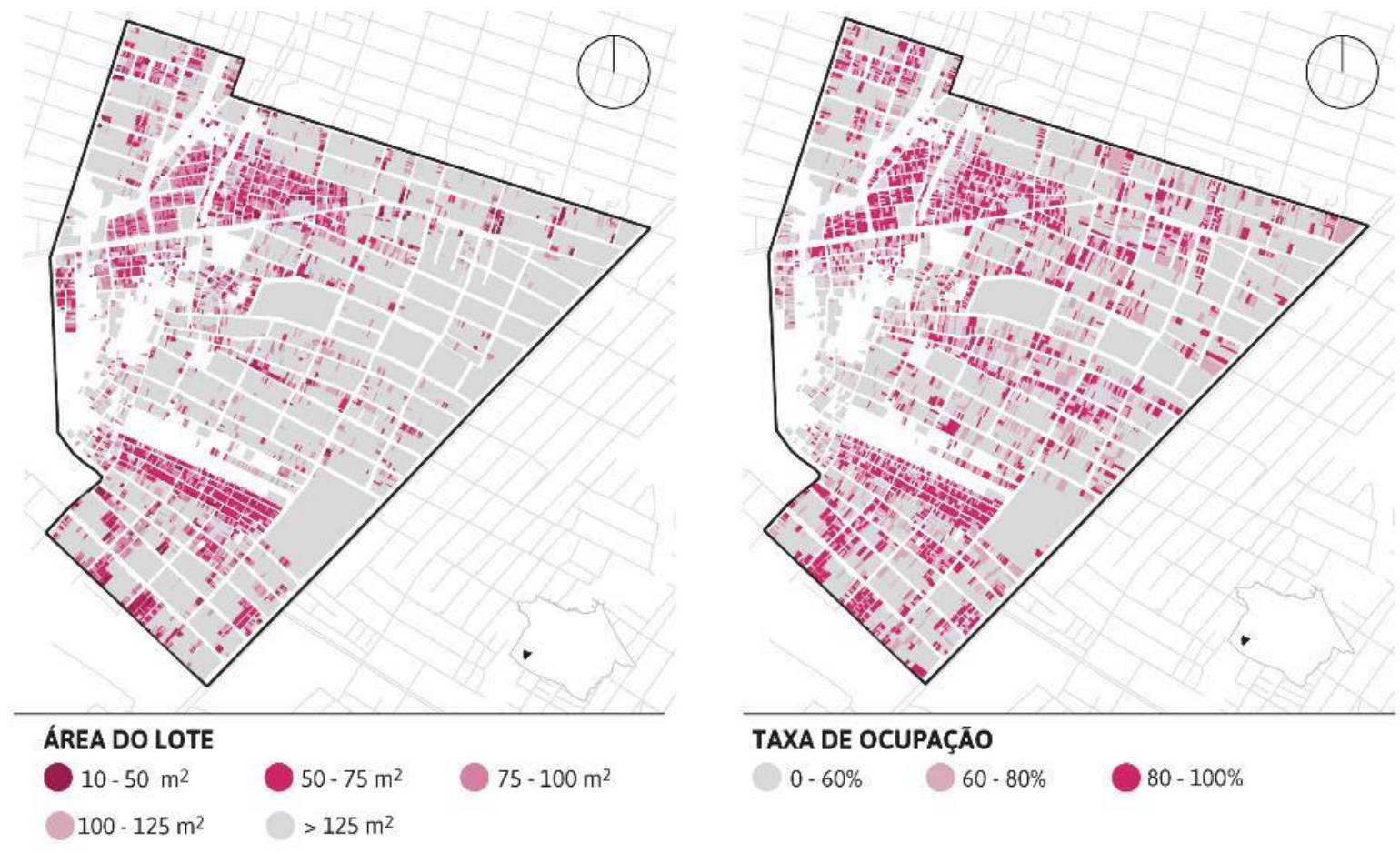

\section{TAXA DE OCUPAÇÃO}

$0-60 \% \bigcirc 0-80 \%$

$80-100 \%$

Figura 9 - Área dos lotes e taxas de ocupação na ZEIS Bom Jardim Fonte: Elaborada pelos autores (2019).

Para ilustrar a análise na escala do tecido, a Figura 10 ilustra dois assentamentos precários (tecidos) com grande diferença em seus respectivos graus de consolidação. Apresenta ainda a frequência estatística das áreas dos lotes e das taxas de ocupação. A aplicação do método produz evidencias de que o assentamento de Nova Canudos (mais antigo, ocupado na década de 1990) possui pouco espaço livre disponível, seja na escala do lote ou na escala do tecido. Por outro lado, o assentamento de Marrocos (mais recente, ocupado nos anos 2000) tem ruas mais largas, lotes maiores com baixa taxa de ocupação e maior disponibilidade de áreas de lazer improvisadas.

Interessante perceber que esses resultados quantitativos não correspondem à percepção de qualidade urbanística dos moradores, que consideram o assentamento Nova Canudos mais desenvolvido que o assentamento Marrocos. Isso porque o primeiro possui maior disponibilidade de infraestrutura (pavimentação, iluminação e drenagem parcial) se comparado com o segundo. Por outro lado, o depoimento dos moradores revela como a implantação de infraestrutura desacompanhada de regulação e controle urbano pode levar a uma maior precarização urbanística tendo em vista a tendência de excessivo adensamento construtivo apresentado. 


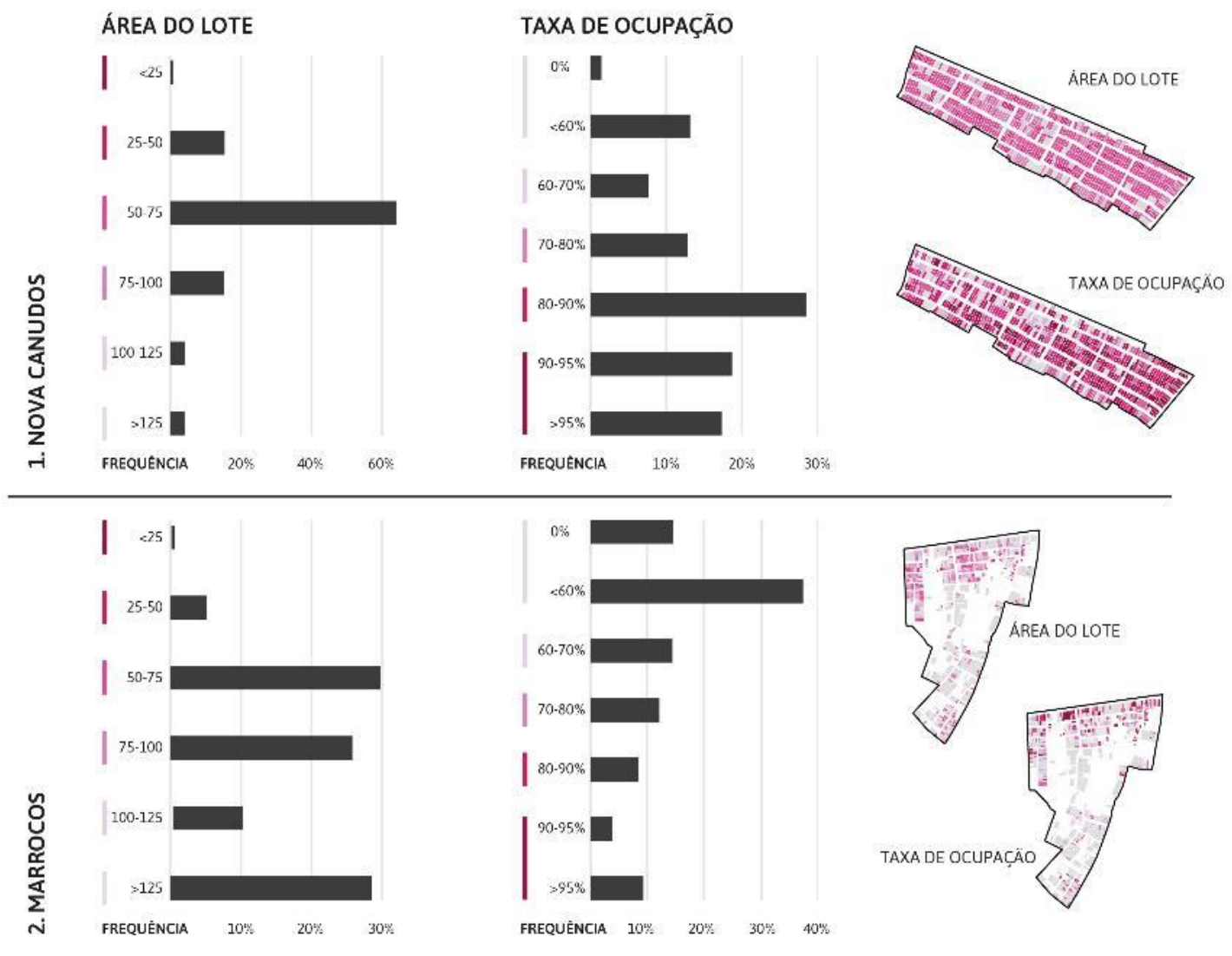

Figura 10 - Comparação da frequência das áreas dos lotes e taxas de ocupação nos assentamentos "Nova Canudos" e "Marrocos"

Fonte: Elaborada pelos autores (2019).

Para além da análise na escala dos tecidos, fizemos um estudo dos dados produzidos na totalidade ZEIS. Em geral os problemas podem ser observados em um nível de unidade habitacional. De acordo com as aferições realizadas, mais de $60 \%$ dos lotes têm uma área abaixo do mínimo de $125 \mathrm{~m}^{2}$, que é a área mínima legal estabelecida pelo Plano Diretor atual, sem levar em conta as zonas especiais. 0 pequeno padrão de tamanho dos lotes resulta em problemas no que diz respeito à ocupação do lote: entre os lotes com área abaixo de $125 \mathrm{~m}^{2}, 81 \%$ têm taxa de ocupação acima de $60 \%$, que é o máximo permitido pelo mesmo plano.

0 método também permitiu identificar algumas tendências de ocupação a partir da introdução da dimensão temporal: com tínhamos disponíveis os dados de 1995, foi realizada uma comparação da ocupação do solo e da verticalização entre 1995 e 2010 mediante aplicação do algoritmo apresentado na Figura 7 aos respectivos dados dessas datas (ver Figura 11). Diagnosticamos, de uma maneira geral, um aumento da sua ocupação na escala do lote, notadamente a partir da frente até o fundo do terreno, o que ocorre, em geral, por toda a ZEIS. É possível observar a ocupação gradual da área do lote pelo edifício até que permaneça apenas um mínimo de área livre para tarefas como a secagem de roupas. Só então começa o processo de verticalização, o qual ainda é insignificante na área nesses 15 anos. 


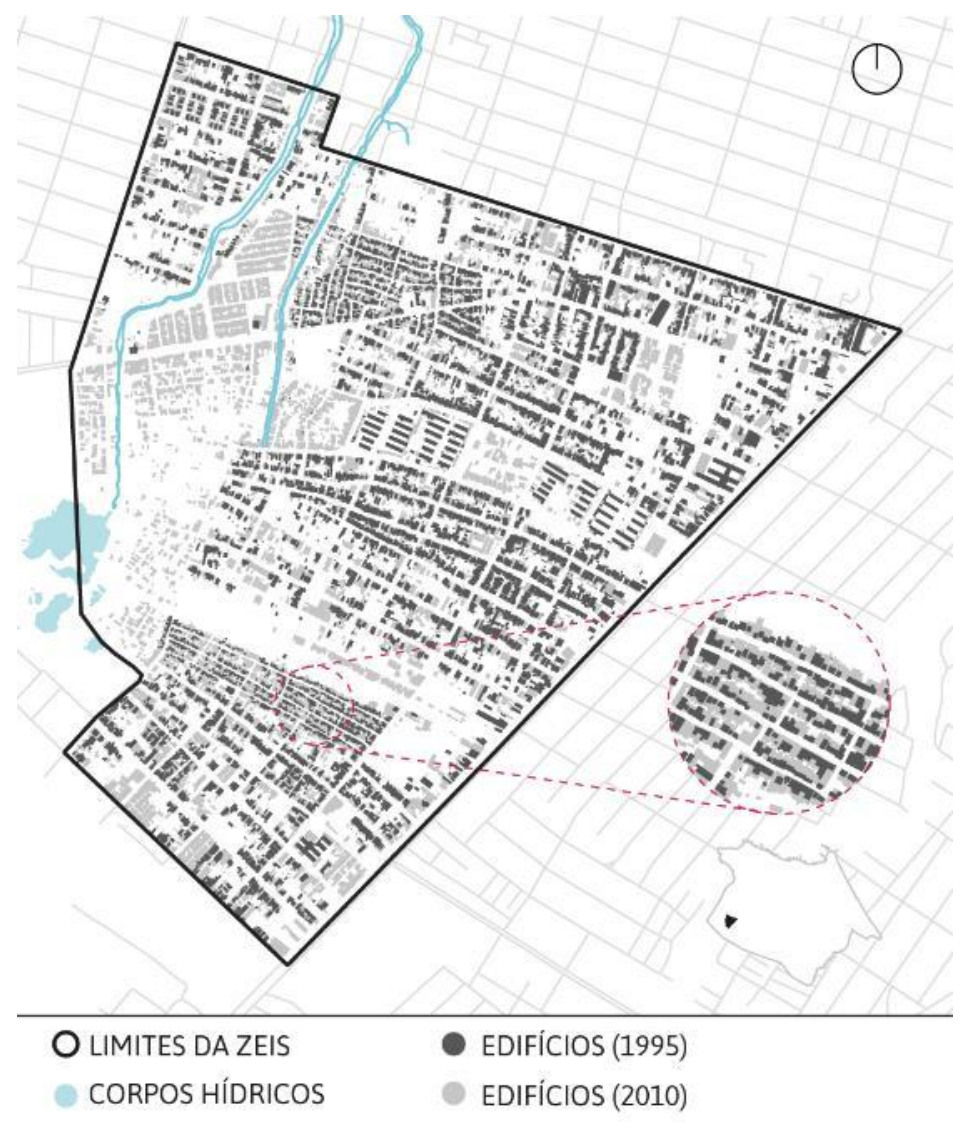

Figura 11 - Comparação da ocupação em 1995 e 2010 na ZEIS Bom Jardim Fonte: Elaborada pelos autores (2019).

Por outro lado muitos novos lotes surgiram e o território da ZEIS está significativamente mais ocupado. A área ocupada dobrou entre 1995 e 2010, de uma ocupação de cerca de 15\% para 32\% da área total. Isso significa que metade da ocupação existente em 2010 ocorreu dentro desse período de 15 anos. A sobreposição das novas edificações com os limites das áreas ambientalmente frágeis revelou ainda uma situação mais grave: há um avanço gradual da ocupação em áreas ambientalmente frágeis. Considerando os limites das áreas de risco apontadas pelo PLHIS (Fortaleza, 2016), os edifícios que em 1995 ocupavam 3\% dessas áreas, passaram a ocupar 22\% em 2010.

Embora uma previsão de tendência não possa ser definida com precisão, essa análise temporal emite alguns alertas. Na ausência de qualquer tipo de controle da qualidade do espaço produzido, é provável que a ocupação se estenda ainda mais para as áreas ambientalmente frágeis e se intensifique em áreas já ocupadas, reduzindo a permeabilidade do solo e aumentando os riscos de inundação. Além disso, áreas vazias que poderiam ser desapropriadas para prover habitação de interesse social, áreas de lazer e equipamentos sociais estão sujeitas a um processo rápido de apropriação. No longo prazo, especialmente se houver provisão de infraestrutura desacompanhada de medidas de controle urbano, o solo tende a se tornar cada vez mais intensamente ocupado e, posteriormente, os edifícios tendem a se tornar verticais, o que imporá problemas de falta de insolação e ventilação, além os problemas já existentes de acessibilidade, drenagem e falta de espaços públicos.

O exercício de ler os padrões de uso e ocupação do solo na área estudada revelou, de fato, sua clara dissociação com a regulação urbanística vigente, estabelecida no Plano Diretor (CMFor, 2009). Mesmo na terra relativamente barata nos arredores de Fortaleza os parâmetros urbanos legais não são atendidos pela população, seja por causa das práticas especulativas dos proprietários dos lotes nos loteamentos aprovados, seja devido a um ambiente de total ausência de controle urbano pelo estado. 


\section{Considerações finais}

Historicamente, em Fortaleza, o fato de a maior parte da cidade ter características não permitidas pelo plano anterior foi sistematicamente ignorado por cada plano subsequente e esse processo continua a ser reproduzido no sistema de planejamento atual. A cidade precária tem sido ignorada pelos planos urbanos e nunca foi colocada como um dos maiores desafios das políticas urbanas ${ }^{3}$. Embora uma parte significativa da cidade esteja fora do escopo da regulação, na narrativa dominante a cidade informal é composta de assentamentos precários ou favelas, nunca por aquele prédio que excede a altura máxima permitida. Em Fortaleza com $40 \%$ de seus 2,5 milhões de habitantes vive em assentamentos informais precários (Fortaleza, 2016), a distinção entre formal e informal está intimamente ligada a uma carga simbólica que tanto condiciona quanto é condicionada pela falta de informação sobre a cidade real.

Identificamos em Fortaleza, e mais especificamente em nosso estudo sobre a ZEIS Bom Jardim, a enorme contradição dos efeitos do zoneamento vigente na dinâmica urbana real, já denunciada pela literatura brasileira. 0 caso da ZEIS Bom Jardim fornece evidências de que a regulação permanece desconectada da cidade real e persiste incapaz de informar novos procedimentos. Ao definir o limite entre os padrões legais e ilegais uma grande parcela da população que não tem acesso ao padrão da cidade "planejada" é empurrada para a ilegalidade e/ou para a periferia. 0 discurso da cidade caótica — ou não planejada — esconde mais do que revela sobre as reais causas da persistência da informalidade urbana nas cidades brasileiras.

Diante do atual quadro de desmonte da politica nacional de urbanização dos assentamentos precários (Cardoso \& Denaldi, 2018), diversos autores têm apontado as limitações intrínsecas das iniciativas de regularizar fundiária que abordam somente a dimensão jurídica (Fernandes, 2012). Para além dos investimentos em infraestrutura, faz-se necessário estabelecer algum tipo de diretriz e/ou normas de uso e ocupação do solo de forma a gerir o desenvolvimento dos assentamentos precários de origem informal. Para que se atenuem as inseguranças e, sobretudo, para que se recoloque nos ombros do estado a responsabilidade de assegurar condições básicas de habitabilidade aos moradores, é necessário haver controle urbano (Moretti \& Amore, 2019). Por mais que o controle urbano nas cidades brasileiras de uma maneira geral seja falho, a existência de uma norma de uso e ocupação do solo passível de ser aplicada é condição sine qua non para mudar o cenário. Ainda que os desafios políticos pareçam intransponíveis e precisem estar em pauta, não se pode deixar de discutir os entraves técnicos da regulação de assentamentos informais, entre os quais está a necessidade de conhecimento da situação existente e de visualização da situação proposta. Uma regulação voltada para a qualificação dos assentamentos informais demanda, antes de tudo, a compreensão da realidade local, para a qual a sua representação é fundamental. A modelagem da informação contribui, nesse sentido, ao possibilitar que, a partir de dados geométricos simples, produza-se uma vasta gama de informações urbanísticas, de modo que os assentamentos analisados sejam representados não mais como manchas amorfas e opacas, mas enquanto forma urbana, enquanto cidade.

Ao reduzir o custo de tempo e de recursos para produzir informações geográficas sobre espaços precários, as novas tecnologias abrem novas possibilidades de atuação para urbanistas engajados na efetivação de políticas urbanas efetivamente transformadoras. Ao invés de substituir a necessidade de ida a campo, as novas tecnologias facilitam ao diálogo com os moradores, visto que permitem uma maior apropriação/familiaridade com o território estudado. Tornam-se, portanto, um instrumento adequado para iniciar o processo de familiarização dos atores envolvidos (representantes do estado, pesquisadores, moradores) com o contexto urbanístico que se pretende qualificar, e em especial com os padrões morfológicos existentes. Produzem ainda dados precisos sobre os problemas a serem sanados, como a quantificação/mensuração da tendência de precarização do território. No território estudado essa tendência ocorre de várias formas, seja através de aumento demasiado das taxas de ocupação internas ao lote, seja através do avanço da urbanização sobre as áreas frágeis. Em um contexto político onde a dificuldade de diálogo entre os diversos atores urbanos é recorrente, contar com uma base de dados especializada de alta qualidade pode vir a ser um instrumento importante para a efetivação de uma política urbana democrática.

\footnotetext{
3 O Plano Diretor vigente em Fortaleza (CMFor, 2009) avança no sentido de reverter esse processo, especialmente ao estabelecer as Zonas Especiais de Interesse Social tanto em áreas precárias existentes como em vazios urbanos. As diversas gestões, entretanto, não foram capazes de implementar tais instrumentos urbanísticos, tendo agido no sentido de neutralizar seus efeitos. Porém a mera presença de instrumentos distributivos como a ZEIS na letra da lei possuiu o mérito de evidenciar disputas pelo solo urbanizado.
} 


\section{Referências}

Almeida, A. P. (2014). (Grande) Bom Jardim: Reterritorialização e Política de Representação à Luz da Nova Pragmática (Dissertação de Mestrado). Programa de Pós-graduação em Linguística Aplicada, Universidade Estadual do Ceará, Fortaleza.

Ancona, A. (2010). Guia para o Mapeamento e Caracterização de Assentamentos Precários. Brasilia: MCidades/SNH.

Berghauser Pont, M., \& Haupt, P. (2010). Spacematrix: Space, Density and Urban Form. Rotterdam: NAi Publishers.

Bezerra, L. M. (2015). Pobreza e Lugar(es) nas margens urbanas: Lutas de classificação em territórios estigmatizados do Grande Bom Jardim (Tese de doutorado). Programa de Pós-Graduação em Sociologia, Universidade Federal do Ceará, Fortaleza.

Câmara Municipal de Fortaleza (CMFor), Sistema de Apoio ao Processo Legislativo (1963, 20 de março). Lei n. 2128, de 20 de março de 1963. Aprova o Plano Diretor da Cidade de Fortaleza e dá outras providências. Diário Oficial do Município de Fortaleza, ano IX, n. 2741, 23 mar. 1963. Recuperado em 11 de novembro de 2019, de https://sapl.fortaleza.ce.leg.br/media/sapl/public/normajuridica/1963/10809/le21281963.pdf.

Câmara Municipal de Fortaleza (CMFor), Sistema de Apoio ao Processo Legislativo (1979, 13 de março). Lei n. 5122-A, de 13 de março de 1979. Dispõe sobre o parcelamento, uso e ocupação do solo urbano e dá outras providências. Diário Oficial do Município de Fortaleza, ano XXVI, n. 6639, 24 abr. 1979. Recuperado em 11 de novembro de 2019, de https://sapl.fortaleza.ce.leg.br/media/sapl/public/normajuridica/1979/5832/5122-a.pdf

Câmara Municipal de Fortaleza (CMFor), Sistema de Apoio ao Processo Legislativo (1981, 17 de dezembro). Lei $n$. 5.530, de 17 de dezembro de 1981. Dispõe sobre o Código de Obras e Posturas do município de fortaleza e da outras providências. Diário Oficial do Município de Fortaleza, ano XXIX, n. 7299, 18 dez. 1981. Recuperado em 11 de novembro de 2019, de https://sapl.fortaleza.ce.leg.br/media/sapl/public/normajuridica/1981/1844/1844_texto_integral.pdf

Câmara Municipal de Fortaleza (CMFor), Sistema de Apoio ao Processo Legislativo (1992, 16 de janeiro). Lei n. 7061, de 16 de janeiro de 1992. Aprova o Plano Diretor de Desenvolvimento Urbano de Fortaleza - PDDU-For e dá outras providencias. Diário Oficial do Município de Fortaleza, ano XXXIX, n. 9788, 20 jan. 1992. Recuperado em 11 de novembro de 2019 , de https://sapl.fortaleza.ce.leg.br/media/sapl/public/normajuridica/1992/780/780_texto_integral.pdf

Câmara Municipal de Fortaleza (CMFor), Sistema de Apoio ao Processo Legislativo (2009, 2 de fevereiro). Lei Complementar n. 062, de 2 de fevereiro de 2009. Institui o Plano Diretor Participativo do Município de Fortaleza e dá outras providências. Fortaleza: Diário Oficial do Município de Fortaleza, ano LVI, n. 14.020, 13 mar. 2009. Recuperado em 11 de novembro de 2019, de https://sapl.fortaleza.ce.leg.br/media/sapl/public/normajuridica/2009/107/107_texto_integral.pdf

Cardoso, A. L.; \& Denaldi, R. (Orgs.) (2018). Urbanização de favelas no Brasil: um balanço preliminar do PAC (1a ed.). Rio de Janeiro: Letra Capital.

Castells, M., \& Portes, A. (1989). World underneath: The origins, dynamics, and effects of the informal economy. In A. Portes (ed.), The informal economy: Studies in advanced and less developed countries. Baltimore, MD: Johns Hopkins University Press.

Castells, M. (1999). A sociedade em rede. São Paulo: Paz e Terra.

Costa Lima, M. (2017). Ver a cidade: modelagem da informação para regulação de assentamentos informais (Dissertação de Mestrado). Programa de Pós-graduação em Arquitetura e Urbanismo e Design, Universidade Federal do Ceará, Fortaleza.

Denaldi, R; \& Fonseca, M. de L. P. (2012). Relatório Final do Projeto de Extensão Planos Locais de Habitação de Interesse Social na Região Metropolitana de São Paulo. Recuperado em 11 de junho de 2019, de www.lepur.com.br/wpcontent/uploads/2017/12/07-Planos-Locais-de-Habita\%C3\%A7\%C3\%A3o-de-Interesse-Social-na-Regi\%C3\%A3oMetropolitana-de-S\%C3\%A3o-Paulo.pdf

Fernandes, E. (2012). Regularization of informal settlements in Latin America (Policy Focus Report). Cambridge, MA: Lincoln Institute of Land Policies. 
Fortaleza (2016). Plano de Habitação de Interesse Social. In Fortaleza. Plano Fortaleza 2040: equidade social, territorial, e econômica (Vol. 2). Fortaleza: Iplanfor.

Freitas, C., Gomes, V., \& Borges, M. (2013). Planejamento urbano com uso de sistema de informação geográfica: o caso de Feira de Santana-BA. Universitas: Arquitetura e Comunicação Social, 10(1), 35-45. DOI http://dx.doi.org/10.5102/uc.v10i1.1947

FREITAS, Clarissa Figueiredo Sampaio. Ilegalidade e degradação em Fortaleza: os riscos do conflito entre a agenda urbana e ambiental brasileira. urbe, Rev. Bras. Gest. Urbana [online]. 2014, vol.6, n.1, pp.109-125. ISSN 2175-3369. http://dx.doi.org/10.7213/urbe.06.001.AC02

Clarissa F. Sampaio Freitas (2019) Insurgent planning? Insights from two decades of Right to the City in Fortaleza, Brazil, City, 23:3, 285-305, DOI: 10.1080/13604813.2019.1648030

Freitas, C., Araújo, R., Costa Lima, M., Silva, E., Frota, N., \& Alves, M. (2019). Plano Popular da Zeis Bom Jardim. Fortaleza: Imprensa Universitária UFC. Recuperado de http://www.repositorio.ufc.br/handle/riufc/46151, em 12 nov. 2019.

Instituto Brasileiro de Geografia e Estatística (IBGE) (2010). Censo demográfico 2010. Rio de Janeiro: IBGE.

Kanbur, R. (2009). Conceptualising Informality: Regulation and Enforcement. Discussion Paper No. 4186. Bonn: Cornell University \& IZA.

Magalhães, A. (2013). O direito das favelas. Rio de Janeiro: Letra Capital.

Maricato, E. (2013) As ideias fora do lugar e o lugar fora das ideias. In O. Arantes, C. Vainer, \& E. Maricato. A cidade do pensamento único: Desmanchando consensos (p. 121-192). Petrópolis: Vozes.

Martins, M. (2006). Globalização, Informalidade e Regulação em Cidades Latino-Americana. Cadernos PROLAM/USP, São Paulo, 5(10), 31-49. https://doi.org/10.11606/issn.1676-6288.prolam.2006.81798

Moreira, T. A.; \& Ribeiro, J. A. (2016). A questão fundiária brasileira no desenho das políticas nacionais de habitação: considerações a partir do início do século XXI. Cad. Metrop., São Paulo, 18(35), 15-32. http://dx.doi.org/10.1590/22369996.2016-3501

Moretti, R., \& Amore, C. S. (2019). Direito à legalidade e retomada do controle público sobre a produção da cidade. BR Cidades. Recuperado em 12 de junho de 2019, de http://observatoriodasmetropoles.net.br/wp/direito-legalidade-eretomada-do-controle-publico-sobre-producao-da-cidade/

Mukhija, V., \& Loukaitou-Sideris, A. (2015). Reading the Informal City: Why and How to Deepen Planners' Understanding of Informality. Journal of Planning Education and Research, 35(4), 444-454.

https://doi.org/10.1177/0739456X15591586

Pequeno, R., \& Freitas, C. (2012). Desafios para implementação de Zonas Especiais de Interesse Social em Fortaleza. Cad. Metrop., São Paulo, 14(28), 485-505. https://doi.org/10.1590/14819

Pereira, G. C., \& Silva, B. N. (2001). Geoprocessamento e Urbanismo. In L. H. Gerardi, \& I. A. Mendes (Eds.), Temas da Geografia Contemporânea. Rio Claro: Programa de Pós-Graduação em Geografia - UNESP: AGETEO.

Prefeitura de Fortaleza (1932, 13 de dezembro). Decreto n. 70, de 13 de dezembro de 1932. Põe em execução o Código de Posturas do Município de Fortaleza. Arquivo digitalizado a partir de cópias de microfilmes dos Jornais existentes no Arquivo Público do Estado do Ceará. Recuperado em 26 de setembro de 2016, de http://acervo.fortaleza.ce.gov.br/

Prefeitura de Fortaleza (1950, 16 de maio). Lei n. 188, de 16 de maio de 1950. Dispõe sobre o Código Urbano do Município de Fortaleza. Diário Oficial do Município de Fortaleza, ano I, n. 107, 29 nov. 1952. Recuperado em 6 de setembro de 2016, de http://acervo.fortaleza.ce.gov.br/

Rolnik, R. (1997). A cidade e a lei: legislação, política urbana e territórios na cidade de São Paulo. São Paulo: Studio Nobel: Fapesp.

Rolnik, R. (2015). Guerra dos Lugares: A colonização da terra e da moradia na era das finanças. São Paulo: Boitempo.

Roy, A., \& Alsayyad, N. (Eds.) (2004). Urban Informality: Transnational Perspectives from the Middle East, Latin America and South Asia. Lanham-MD: Lexington Books.

Roy, A. (2005). Urban Informality: Toward an Epistemology of Planning. Journal of the American Planning Association, Chicago, 71(2), 147-158. https://doi.org/10.1080/01944360508976689 
Roy, A. (2009). Why India Cannot Plan Its Cities: Informality, Insurgence and the Idiom of Urbanization. Planning Theory, Sage Journals, 8, 76-87. https://doi.org/10.1177/1473095208099299

Santos, M. (2008). Técnica espaço tempo: Globalização e meio técnico-científico-informacional. (5a ed.). São Paulo: Edusp.

Smolka, M. (2003). Regularização da Ocupação do Solo Urbano: 0 problema que é parte da solução, a solução que é parte do problema. In P. Abramo (Org.), A Cidade da Informalidade: o desafio das cidades latino-americanas (p. 199138). Rio de Janeiro: Livraria Sette Letras: FAPERJ.

Sousa, C. (2018). Modelando a Percepção: O ambiente do patrimônio cultural edificado na regulação da forma urbana (Dissertação de Mestrado). Programa de Pós-graduação em Arquitetura e Urbanismo e Design, Universidade Federal do Ceará, Fortaleza.

Terzidis, K. (2004). Algorithmic Design: A Paradigm Shift in Architecture? In Anais do Congresso eCAADe’22 (p. $201-$ 207). Copenhagen, Royal Danish Academy of Fine Arts.

UN-Habitat (2010). State of the World Cities 2010/2011: Bridging the Urban Divide. London: Earthscan for Un-Habitat.

Vainer, C. (2011). Cidade de Exceção: Reflexões a Partir do Rio de Janeiro. In Anais do XIV Encontro Nacional da Associação Nacional de Planejamento Urbano (Vol. 14). Rio de Janeiro: ANPUR. Recuperado em 07 de maio de 2019 , de http://anais.anpur.org.br/index.php/anaisenanpur/article/view/635/622.

Villaça, F. (1995). A crise do planejamento urbano. São Paulo em Perspectiva, 9(2), 45-51.

Editor responsável: Paulo Nascimento Neto

Recebido: 02 nov. 2018

Aprovado: 02 out. 2019 